\title{
The 2-Methoxy methyl analogue of salvinorin A attenuates cocaine-induced drug seeking and sucrose reinforcements in rats
}

\author{
Aashish S. Morani ${ }^{\mathrm{a}}$, Amy Ewald $^{\mathrm{a}}$, Katherine M. Prevatt-Smith ${ }^{\mathrm{b}}$, Thomas E. Prisinzano ${ }^{\mathrm{b}}$, and \\ Bronwyn Kivella,
}

aSchool of Biological Science, Victoria University of Wellington, PO Box 600, Wellington, New Zealand bepartment of Medicinal Chemistry, University of Kansas, Lawrence, Kansas 66045, USA

\begin{abstract}
$\kappa$ opioid receptor activation by traditional arylacetamide agonists and the novel neoclerodane diterpene $\kappa$ opioid receptor agonist Salvinorin A (Sal A) results in attenuation of cocaine-seeking behavior in pre-clinical models of addiction. However, adverse effects such as sedation, depression and aversion limit their clinical utility. The Sal A analogue, 2-methoxymethyl salvinorin B (MOM Sal B) is a longer acting Sal A analogue with high affinity for $\kappa$ opioid receptors. In this study, we tested MOM Sal B for its ability to modulate cocaine-seeking behavior in rats. MOM Sal B $(0.3 \mathrm{mg} / \mathrm{kg})$ successfully attenuated cocaine-seeking but also attenuated sucrose reinforcement. No change in activity was observed in either cocaine-induced hyperactivity or spontaneous open field activity tests but increased immobility and decreased swimming times in the forced swim test were observed. This study indicates that $\kappa$ opioid receptor activation by more potent Sal A analogues modulates cocaine-seeking behavior non-selectively without causing sedation, suggesting an improved side effects profile. However, pro-depressive effects are seen, which may limit the therapeutic potential of this compound. Future studies with Sal A analogues having affinities at other opioid receptors are warranted as they have the potential to identify compounds having effective anti-addiction properties.
\end{abstract}

\section{Keywords}

Cocaine; self-administration; salvinorin A; sucrose reinforcement; locomotion; forced swim test

\section{Introduction}

Attenuation of drug self-administration by acute $\kappa$ opioid receptor activation has been shown in rodents (Glick et al., 1995) and non-human primates (Mello and Negus, 1998). Behavioral effects of cocaine (Heidbreder et al., 1993, 1995), amphetamine (Gray et al., 1999), and nicotine (Hahn et al., 2000) have also been antagonized by pre-treatment with $\kappa$

(C) 2013 Elsevier B.V. All rights reserved.

*Corresponding author. Tel.: +644 463 5233x8336; fax: +644 463 5331. bronwyn.kivell@ vuw.ac.nz.

Publisher's Disclaimer: This is a PDF file of an unedited manuscript that has been accepted for publication. As a service to our customers we are providing this early version of the manuscript. The manuscript will undergo copyediting, typesetting, and review of the resulting proof before it is published in its final citable form. Please note that during the production process errors may be discovered which could affect the content, and all legal disclaimers that apply to the journal pertain. 
opioid receptor agonists. These findings have prompted further studies into the potential development of these compounds as anti-addiction pharmacotherapies (Prisinzano et al., 2005; Shippenberg et al., 2001, 2007), particularly in the binge or intoxication phase where $\kappa$ opioid agonists antagonise the rewarding effects of drugs of abuse, for recent reviews see (Butelman et al 2012; Shippenberg 2009, Wee and Koob 2010). However, adverse side effects including sedation (Butelman et al., 2007, 2009), dysphoria (Pfeiffer et al., 1986; Walsh et al., 2001) and depression (Todtenkopf et al., 2004) have limited the clinical development of traditional acrylacetamide $\kappa$ opioid agonists. Antagonists of $\kappa$ opioid receptors have been suggested to have therapeutic use later in the addiction cycle as they have been shown to modulate stress pathways in addiction (Chavkin 2011).

Sal A, a neoclerodane diterpene derived from Salvia divinorum, was shown to selectively bind with high affinity to $\kappa$ opioid receptors (Roth et al., 2002). Therefore, Sal A, a nonnitrogenous $\kappa$ opioid receptor agonist has characterized a novel class of $\kappa$ opioid receptor ligand. Sal A binds to $\kappa$ opioid receptors with greater potency than U69593 or U50488H (Chavkin et al., 2004) and is 40-fold less potent than U50488H in its ability to internalize $\kappa$ opioid receptors (Wang et al., 2005). These findings suggest that although it is a potent $\mathrm{K}$ opioid receptor agonist, Sal A might differ pharmacologically and behaviorally from traditional arylacetamide $\kappa$ opioid receptor agonists (Beguin et al., 2012; Fantegrossi et al., 2005; Prisinzano, 2005).

In vivo studies with Sal A have shown that it has a rapid onset of action (approx $5 \mathrm{~min}$ ) and an elimination half-life of approximately 50 min (Butelman et al. 2009; Hooker et al., 2008; Schmidt et al., 2005). The short duration of action is thought to be due to its rapid metabolism at position C-2 to a pharmacologically inactive metabolite, salvinorin B (Beguin et al., 2005; Chavkin et al., 2004). However, other mechanisms are likely involved as well (Butelman et al., 2012). Structure activity relationships have revealed the importance of the C-2 acetoxy group for binding to and activation of $\kappa$ opioid receptors (Beguin et al., 2008; Prisinzano and Rothman, 2008; Prevatt-Smith et al., 2011). Sal A analogues with C-2 substitution such as MOM Sal B have been shown to have a longer half-life in vivo (Baker et al., 2009; Wang et al., 2008). In vitro studies indicate that it is five- and seven-fold more potent at $\kappa$ opioid receptors than $\mathrm{U} 50488 \mathrm{H}$ and Sal A, respectively (Wang et al., 2008). Behavioral pharmacology studies with MOM Sal B have shown antinociception, motor suppression, hypothermia and diuresis (Inan et al., 2009; Wang et al., 2008). Recent reports show that MOM Sal B completely substituted for U50488H and Sal A in discriminative stimulus tests in rats (Peet and Baker, 2011). Work has been reported with Sal A analogues characterizing their anti-addiction profiles (Chartoff et al., 2008; Morani et al., 2009, 2012). Therefore, we tested the effect of MOM Sal B on cocaine-seeking using a cocaine prime induced reinstatement paradigm in rats (Dewit and Stewart, 1981, 1983). We also tested the effect of MOM Sal B on motor function (spontaneous locomotion and cocaine induced hyperactivity), reward reinforcement (sucrose reinforcement) and depression (forced swim test, FST).

\section{Materials and Methods}

\subsection{Subjects}

Male Sprague-Dawley rats weighing 325-350 g (for cocaine self-administration), 250-300 g (for sucrose reinforcement and spontaneous locomotion tests) and 350-400 $\mathrm{g}$ (for forced swim test) were used. Self-administering rats were housed individually in hanging polycarbonate cages in a temperature and humidity $\left(55 \%\right.$ relative humidity, $19-21^{\circ} \mathrm{C}$ ) controlled room. Rats used for sucrose reinforcement, spontaneous locomotion and forced swim tests were housed in groups of 2-3 per cage. The lights were maintained on a 12/12 h cycle with lights on at $0700 \mathrm{~h}$. Animals used for reinstatement tests, locomotion experiments 
and forced swim tests had free access to food and water except during testing. Animals tested for sucrose reinforcements had free access to water within their home cages and were maintained at approximately $85 \%$ of their initial feeding weights during the experiments by restricting access to food. The animal colonies were maintained at the School of Psychology, Victoria University of Wellington. All experimental procedures were reviewed and approved by the Animal Ethics Committee of Victoria University of Wellington, New Zealand.

\subsection{Surgery}

Under deep anesthesia produced by ketamine/xylacine ( $90 / 9 \mathrm{mg} / \mathrm{kg}$, intraperitoneal, i.p.), the right external jugular vein was isolated and a silastic catheter was inserted. The distal end (22 gauge stainless steel tubing) was passed subcutaneously (s.c.) to an exposed portion of the skull where it was fixed to embedded jeweler's screws with dental acrylic. Rats received carprofen $(5 \mathrm{mg} / \mathrm{kg}$, s.c.) at 0,24 , and $48 \mathrm{~h}$ post-surgery. In order to prevent infection and clot formation, the catheters were daily infused with $0.1 \mathrm{ml}$ of a sterile saline solution containing heparin $(30.0 \mathrm{U} / \mathrm{ml})$, penicillin G Potassium $(250,000 \mathrm{U} / \mathrm{ml})$ and streptokinase $(8000 \mathrm{U} / \mathrm{ml})$. Testing began five days post-surgery.

\subsection{Apparatus}

2.3.1. Cocaine Self administration-Self-administration training and reinstatement tests were carried out in humidity $\left(55 \%\right.$ relative humidity) and temperature $\left(19-21^{\circ} \mathrm{C}\right)$ controlled rooms containing standard operant chambers equipped with two levers (Med Associates, ENV-001, VT, USA). Depression of the active lever led to a programmed intravenous (i.v.) infusion of a $0.1 \mathrm{ml}$ solution of cocaine hydrochloride dissolved in sterile physiological saline containing heparin $(3.0 \mathrm{U} / \mathrm{ml})$ in order to maintain the patency of the catheter. The infusions were of $12 \mathrm{~s}$ duration and were accompanied by the illumination of a stimulus light located directly above the active lever. This stimulus light remained illuminated throughout each $12 \mathrm{~s}$ cocaine infusion. Depression of the other lever (the inactive lever) was without programmed consequence. Prior to each training and testing session, the catheter lines were infused with $0.1 \mathrm{ml}$ of the heparin-penicillin-streptokinase solution. The stainless steel catheter was connected to the syringe by a length of microbore tubing. After completion of each session, the lines were again infused with $0.1 \mathrm{ml}$ of the heparin-penicillin-streptokinase solution, the stainless steel tubing was plugged, and the animal was returned to its home cage. Drug delivery and data acquisition were controlled by Med Associates software. Cocaine deliveries were made via mechanical pumps (Razel Scientific, Model A with $1.0 \mathrm{rpm}$ motor equipped with $20 \mathrm{ml}$ syringe; VT, USA).

2.3.2. Sucrose self-administration apparatus-Eight standard operant chambers (Med Associates, ENV-008) placed in a light and sound attenuating room were used for training and testing. Each operant chamber had two retractable levers with a bottle delivering $0.1 \mathrm{ml}$ of $10 \%$ sucrose solution in a tray placed on the chamber wall. The sucrose was delivered according to the imposed schedule of reinforcement. Sucrose delivery and data acquisition were controlled by Med Associates software. All experiments were conducted between 0900 and $1600 \mathrm{~h}$.

2.3.3. Locomotion activity tests-Eight Open field chambers (Med Associates ENV-520) were used for this test. Each chamber was equipped with two banks of 16 photocells on each wall to measure horizontal and vertical locomotion. The open field boxes were interfaced with a microcomputer located in an adjacent laboratory. Testing was conducted in the dark between 1000 and $1600 \mathrm{~h}$. White noise was present throughout the experiment. 
2.3.4. Forced swim tests (FST)—The FST chamber was a cylindrical chamber of $44 \mathrm{~cm}$ in height and a diameter of $20 \mathrm{~cm}$ with water level up to a depth of $30 \mathrm{~cm}$. Water temperatures was maintained at $25+1^{\circ} \mathrm{C}$.

\subsection{Procedure}

2.4.1. Cocaine self-administration training and reinstatement test-Rats were trained to self-administer cocaine during daily $2 \mathrm{~h}$ sessions. During each session the animals received an experimenter-delivered infusion of cocaine $(0.5 \mathrm{mg} / \mathrm{kg} /$ infusion (cocaine hydrochloride dissolved in sterile physiological saline containing heparin $(3.0 \mathrm{U} / \mathrm{ml}))$. Thereafter, depression of the active lever produced automated cocaine infusions. Initially the animals were maintained on FR-1 schedule of reinforcement (single infusion following a single lever press). The criterion for acquisition of cocaine self-administration consisted of three consecutive days during which there were at least 20 reinforced responses $(10 \mathrm{mg} / \mathrm{kg}$ during a single session) and a ratio of active: inactive lever responses of at least 2:1. Following acquisition, the reinforcement schedule was increased to FR-5 (five lever presses resulted in a single infusion). Daily $2 \mathrm{~h}$ sessions were conducted until there was less than $20 \%$ variation in responding for three consecutive days. Once responding under the FR-5 schedule was stable, the effect of MOM Sal B pre-treatment on drug seeking was measured. The procedures followed for this test have been described previously (Morani et al., 2009; Schenk et al., 1999, 2001; Schenk and Partridge, 2001). Briefly, testing was conducted on a single day and consisted of three phases. During the first phase the animals were allowed to self-administer cocaine $(0.5 \mathrm{mg} / \mathrm{kg} / \mathrm{infusion}, \mathrm{FR}-5$ schedule of reinforcement) for $1 \mathrm{~h}$. This was followed by a $3 \mathrm{~h}$ phase in which the cocaine solution was replaced by heparinized saline (FR-5 schedule of reinforcement). At the beginning of the third phase the number of responses were recorded for saline reinforcement (FR-5 schedule of reinforcement) for $1 \mathrm{~h}$. Prior to the commencement of this phase, separate groups of rats ( $n=5-6$ per group) received an injection of either vehicle (75\% DMSO, $1 \mathrm{ml} / \mathrm{kg}$, i.p.) or MOM Sal B $(0.03,0.1$ or $0.3 \mathrm{mg} / \mathrm{kg}$, i.p.). All treatments were administered using the Latin square design. Five min following vehicle / MOM Sal B injections, animals received a priming injection of cocaine $(20 \mathrm{mg} / \mathrm{kg}$, i.p. in sterile physiological saline) and active lever responses measured for 60 min. The 5 min pre-treatment time was chosen based on previously published reports on MOM Sal B indicating a rapid onset of action (Baker et al., 2009; Wang et al., 2008).

2.4.2. Oral sucrose self-administration training and reinforcement-Drug naïve rats were trained to orally self-administer $10 \%$ sucrose solution using a daily $45 \mathrm{~min}$ autoshaping procedure. This procedure was repeated for 10 days. Once responding for sucrose was stable, animals were trained on FR-1 schedule of reinforcement, during which pressing the active lever delivered $0.1 \mathrm{ml}$ of a $10 \%$ sucrose solution. Once responding on this schedule was stable, the response requirements were increased to FR-5 (five lever press to receive one infusion). Daily $1 \mathrm{~h}$ sessions were conducted until there was less than $20 \%$ variation in responding for three consecutive days. Once responding on the FR-5 schedule was stable, the effect of MOM Sal B on sucrose-reinforced responding was measured. Rats were treated with either MOM Sal B (0.3 mg/kg, i.p.) or vehicle (75\% DMSO) $5 \mathrm{~min}$ prior to sucrose self-administration, and the number of responses recorded for $60 \mathrm{~min}$.

\subsubsection{Cocaine induced hyperactivity (drug naive and cocaine self} administering rats) -On the test day, separate groups of rats ( $n=5-6$ per group), following a $30 \mathrm{~min}$ habituation phase, were injected with either MOM Sal B $(0.3 \mathrm{mg} / \mathrm{kg}$, i.p.) or vehicle (75\% DMSO, $1 \mathrm{ml} / \mathrm{kg}$, i.p.), $5 \mathrm{~min}$ prior to an injection of cocaine $(20 \mathrm{mg} / \mathrm{kg}$, i.p.). The rats were immediately placed in the activity chambers and total activity, a compilation of horizontal and vertical activity, were measured for a period of $60 \mathrm{~min}$. 
2.4.4. Spontaneous open field activity-On the test day, following a $30 \mathrm{~min}$ habituation phase, drug naïve rats were injected with either vehicle (75\% DMSO, i.p.) or MOM Sal B $(0.3 \mathrm{mg} / \mathrm{kg}$, i.p. $)$ and $5 \mathrm{~min}$ later ambulation counts were measured at $5 \mathrm{~min}$ intervals for $60 \mathrm{~min}$.

2.4.5. Forced swim tests (FST)—Drug-naïve rats were tested using the modified FST method as described in Slattery and Cryan (2012). This method is a modified version of the original FST designed by Porsolt (1979). On day 1, drug-naïve rats were habituated to swimming conditions in the FST chamber for $15 \mathrm{~min}$. The following day, rats were injected with either vehicle (75\% DMSO, i.p.) or MOM Sal B $(0.3 \mathrm{mg} / \mathrm{kg}$, i.p.) $5 \mathrm{~min}$ before being placed into the swim chamber for 5 min. Behavior was recorded using a camera and scored in $5 \mathrm{sec}$ intervals by an observer who was blinded to experimental procedures.

\subsection{Drugs}

Cocaine $\mathrm{HCl}$ (Merck KGaA, Darmstadt, Germany) was dissolved in physiological saline containing heparin $(3.0 \mathrm{U} / \mathrm{ml})$ for all i.v. infusions and in physiological saline for i.p. injections. MOM Sal B (synthesized by Professor Thomas E. Prisinzano, University of Kansas) was suspended in 75\% DMSO. Infusions (i.v.) were in a volume of $100 \mu \mathrm{l}$ and i.p. injections were administered in a volume of $1 \mathrm{ml} / \mathrm{kg}$. All drug weights refer to the salt.

\subsection{Statistical analysis}

Statistical tests were performed using Prism GraphPad 5 software (San Diego, CA). Data for the drug-seeking tests were analyzed using one way ANOVA followed by Tukey post-hoc comparisons. Results for sucrose reinforcements, total activity for cocaine induced hyperactivity and forced swim tests were analyzed using student t-tests. Data for cocaine induced hyperactivity and spontaneous open field activity at $5 \mathrm{~min}$ intervals were analyzed using repeated measures two way ANOVA followed by Bonferroni post hoc tests. One-way repeated measures ANOVA was performed between phases 1 and 2 of the selfadministration test.

\section{Results}

\subsection{Phase 1 and 2 of the reinstatement test}

Figure 1 shows the number of active lever responses during phase 1 and phase 2 of the reinstatement test. Active lever responding during the $60 \mathrm{~min}$ time period comprising phase 1 was high $(102.9 \pm 10.3)$. During phase 2, cocaine solution was replaced with saline and the active lever responses decreased $(11.3 \pm 2.9)(* * * \mathrm{P}<0.001 ; * * * * \mathrm{P}<0.0001)$.

\subsection{Effect of MOM Sal B on cocaine-prime induced reinstatement}

Figure 2 shows the number of lever responses during phase 3. A priming injection of cocaine reinstated extinguished cocaine self-administration behavior; and this behavior was attenuated by pre-treatment with MOM Sal B $[0.3 \mathrm{mg} / \mathrm{kg}, \mathrm{F}(3,17)=4.71, \mathrm{P}<0.05$; Fig. 2]. A non-significant trend towards an increase in the active lever responses following pretreatment with the low doses $(0.03,0.1 \mathrm{mg} / \mathrm{kg})$ of MOM Sal B was also observed $(\mathrm{P}=0.2$ between $0.03 \mathrm{mg} / \mathrm{kg}$ and control and $\mathrm{P}=0.08$ between control and $0.1 \mathrm{mg} / \mathrm{kg}$ in individual ttests).

\subsection{Effect of MOM Sal B on sucrose reinforcement}

Figure 3 shows the effect of MOM Sal B $(0.3 \mathrm{mg} / \mathrm{kg})$ on responding maintained by sucrose reinforcement. MOM Sal B significantly suppressed operant lever press responding for sucrose reinforcements $(\mathrm{P}<0.01)$. 


\subsection{Effect of MOM Sal B on cocaine induced hyperactivity (cocaine self-administering and drug naive rats)}

The effect of MOM Sal B on cocaine produced hyperactivity in cocaine self-administering and drug naive rats are presented Figures 4 and 5 respectively. No significant change in cocaine produced hyperactivity (total activity) was observed following pre-treatment with MOM Sal B in cocaine self-administering $(\mathrm{P}=0.44$; Fig. $4 \mathrm{~A})$ or drug naive rats $(\mathrm{P}=0.24$; Fig. 5A). A further time course comparison also failed to show a significant effect of MOM Sal B pre-treatment on cocaine induced hyperactivity in $[\mathrm{F}(11,108)=1.38, \mathrm{P}=0.0 .19$; Fig. $4 \mathrm{~B}]$ or drug naive rats $[\mathrm{F}(11,110)=1.56, \mathrm{P}=0.24$; Fig. $5 \mathrm{~B}]$.

\subsection{Effect of MOM Sal B on spontaneous open field activity}

Figure 6 shows the effect of MOM Sal B $(0.3 \mathrm{mg} / \mathrm{kg})$ on spontaneous open field activity in drug naïve rats. MOM Sal B had no significant effect on total ambulatory counts measured over a 60 min time period $(\mathrm{P}=0.22$; Fig. $6 \mathrm{~A})$. A further time course analysis revealed no significant effect of MOM Sal B treatment on spontaneous open field activity $[\mathrm{F}(1,12)=$ $1.82, \mathrm{P}=0.20$; Fig. $6 \mathrm{~B}]$. There was also no significant effect on total stereotypy counts or stereotypy counts in bins of 5 min $(P=0.18$; Fig. $6 \mathrm{C}$ and $6 \mathrm{D})$.

\subsection{Effect of MOM Sal B on depressive behavior (FST)}

Figure 7 shows the effect of MOM Sal B $(0.3 \mathrm{mg} / \mathrm{kg})$ on depressive behavior in drug naïve rats. MOM Sal B significantly decreased swimming time and increased immobility time (P $<0.05)$ compared to vehicle. There was no significant change in climbing time.

\section{Discussion}

Results from the present study demonstrate that the longer acting and more potent Sal A analogue, MOM Sal B, significantly attenuates cocaine-seeking in rats. The effect was not due to a generalized impairment of motor function, since MOM Sal B at this dose failed to alter either spontaneous open field activity or cocaine-produced hyperactivity, suggesting that MOM Sal B has no measurable sedative effects at this dose. The effective dose of MOM Sal B $(0.3 \mathrm{mg} / \mathrm{kg})$ also suppresses sucrose reinforced responding.

Previous studies with Sal A have shown that it is effective in attenuating cocaine prime induced reinstatement of drug-seeking behavior (Morani et al., 2009) confirming its antiaddiction effects when administered acutely. Studies have also shown Sal A has an improved side effect profile compared to traditional $\kappa$ opioid receptor agonists. However, Sal A has a short duration of action, limiting its development as an anti-addiction agent. Therefore, there is a need to investigate the pharmacological effects of longer acting Sal A analogues on cocaine induced behaviors. Such studies have the potential to unearth novel anti-cocaine agents. In vivo pharmacological studies have shown that MOM Sal B has a longer duration of action compared to Sal A (Inan et al., 2009; Wang et al., 2008). MOM Sal $\mathrm{B}$ is also more potent than Sal A at $\mathrm{K}$ opioid receptors (Beguin et al., 2005; Munro et al., 2008). Therefore, in this study we screened for pharmacological effects of MOM Sal B on cocaine induced reinstatement in rats.

Our results indicate that an acute injection of MOM Sal B $(0.3 \mathrm{mg} / \mathrm{kg})$ significantly attenuates cocaine-seeking behavior in rats (Fig. 2). The attenuation produced by MOM Sal $\mathrm{B}$ and Sal A were seen at comparable doses $(0.3 \mathrm{mg} / \mathrm{kg}$; (Morani et al., 2009); current study). However, MOM Sal B, at lower doses $(0.03,0.1 \mathrm{mg} / \mathrm{kg})$, showed a non-significant trend towards an increase in cocaine-seeking behavior $(\mathrm{P}=0.2$ and $\mathrm{P}=0.08$ respectively) (Fig. 2). In another study, the arylacetamide $\kappa$ opioid receptor agonist U50488H significantly attenuated cocaine-induced drug seeking in rats $(30 \mathrm{mg} / \mathrm{kg})$ while a 10 fold 
lower dose of U50488H (3 mg/kg) showed a non-significant increase in cocaine-seeking behavior (Morani et al., 2009). A recent study by Baker et al., (2009) showed that MOM Sal B completely substituted for U50488H in discriminative stimulus tests in rats (Baker et al., 2009). These effects produced by MOM Sal B were reversed by pre-treatment with $\kappa$ opioid receptor antagonist, nor-BNI, indicating a $\kappa$ opioid receptor mediated effect. Additionally, U50488H and MOM Sal B had comparable abilities to down-regulate the human $\kappa$ opioid receptor in vitro (Wang et al., 2008). Taken together, these data suggest a similarity in the behavioral pharmacology effects produced by MOM Sal B and U50488H.

Since $\kappa$ opioid receptor activation has been associated with disruptions in natural reward related behaviors; we tested the effect of acute MOM Sal B exposure on oral sucrose reinforcement in rats. A single injection of MOM Sal B at its effective dose $(0.3 \mathrm{mg} / \mathrm{kg})$ significantly suppressed sucrose reinforcements (Fig. 3). Sal A on the other hand attenuated cocaine-seeking without affecting sucrose reinforcement (Morani et al., 2009). These results suggest that the ability to selectively attenuate cocaine-seeking behavior by novel neoclerodane diterpene compounds may reflect their potency at $\kappa$ opioid receptors; with more potent $\kappa$ opioid receptor agonists producing non-selective effects. This is the first study to investigate the anti-addiction and side effect profile of novel Sal A analogues, we do this utilising the preclinical gold-standard self-administration paradigm of cocaine primeinduced relapse to model drug-seeking in humans. One study has investigated the antiaddiction effects of the novel Sal A analogue $\beta$ tetrahydropyran Sal B. This compound has an $\mathrm{ED}_{50}$ in GTP- $\gamma \mathrm{S}$ assays of $60 \pm 6 \mathrm{nM}$ compared to $40 \pm 1 \mathrm{nM}$ for Sal A and $6 \pm 1 \mathrm{nM}$ for Mom Sal B (Prevatt-Smith et al., 2011). However, no side effects were investigated for this compound. The dose required for anti-addiction effects was $1 \mathrm{mg} / \mathrm{kg}$ compared to $0.3 \mathrm{mg} / \mathrm{kg}$ for MOM Sal B. The potency and efficacy at $\kappa$ opioid receptors are likely reasons for the differences in dose required for observation of anti-addiction effects. Previous studies have shown that U50488H suppressed responding to water reinforcement at doses which attenuated cocaine self-administration $(5,10 \mathrm{mg} / \mathrm{kg}$; (Glick et al., 1995)). These results suggest a similar pharmacological effect profile of the more potent Sal A analogue MOM $\mathrm{Sal} B$ with the traditional arylacetamide $\kappa$ opioid receptor agonist U50488H.

In order to determine the effects of MOM Sal B on cocaine hyperactivity, we measured cocaine induced locomotor activity in animals subjected to reinstatement tests (Fig. 4) and in drug naive rats (Fig. 5). Data show a non-significant trend towards attenuation of cocaine induced locomotor activity in both groups that was not significant when total ambulatory counts were analysed over $60 \mathrm{~min}$ or at $5 \mathrm{~min}$ intervals using two-way ANOVA followed by Bonferoni post-hoc tests. Spontaneous open field activity in drug naïve rats following MOM Sal B $(0.3 \mathrm{mg} / \mathrm{kg})$ did not produce motor suppression in drug naive rats (Fig. 6), indicating that MOM Sal B induced attenuation of cocaine-seeking observed in this study was not due to motor suppression. Previous locomotion studies with MOM Sal B suggest that it produced rapid, long lasting (approximately $3 \mathrm{~h}$ ) immobility in mice which was dose dependent and nor-BNI reversible (Wang et al., 2008). However, the same study also showed that MOM Sal B increased locomotion in the Y-maze test in rats. We observed a small but non-significant trend towards an increase in total ambulation counts in drug naïve rats which were treated with MOM Sal B $(0.3 \mathrm{mg} / \mathrm{kg}$; Fig. 6). These findings indicate that the effects of MOM Sal B on motor function might be species related (Wang et al., 2008; current study).

Although Sal A has shown promising anti-cocaine effects, its poor pharmacokinetic profile limits its clinical use. This study highlights that the longer acting, more potent Sal A analogue, MOM Sal B, successfully produces anti-addiction behaviors without sedative effects. However, MOM Sal B does suppress natural reward seeking behavior as shown by sucrose reinforcement testing. A recent review by Wee and Koob (2010) highlights the 
unknown mechanism underlying the ability of the kappa system to modulate addiction and the variability of its effects seen in the literature. While $\kappa$ opioid receptor agonists have been suggested to exert these effects by inducing aversive and punishment-like effects, this requires further clarification (Wee and Koob, 2010). Recently, a study by Harden et al (2012) showed that following chronic mild stress, Long-Evans rats given Sal A (1 mg/kg) restored preference for a sucrose solution, suggesting antidepressant effects (Harden et al., 2012). However in the FST model of depression, Sal A $(0.3 \mathrm{mg} / \mathrm{kg})$ in Sprague-Dawley rats showed pro-depressive effects (Morani et al., 2012). Reasons underlying these differences could be related to the choice of behavioural model used. The FST test applies the stressor at the time of testing, whereas the chronic mild stress model applies the stressor prior to testing. The latter model may in fact prove to be a better model to study stress in relation to addiction behaviours. To our knowledge there have been no tests utilising this cronic mild stress models with any Sal A analogue to date. Further studies will be needed to confirm if this is the case for novel Sal A analogues. The present study adds to these recent findings by suggesting that potent $\kappa$ opioid receptor activation by MOM Sal B impairs natural reward without sedation, whereas previously we showed Sal A does not impair natural reward or cause sedative effects at the minimum effective anti-addiction dose of $0.3 \mathrm{mg} / \mathrm{kg}$. Therefore based on these current findings, we propose that ligands having Sal A like structures with less potency for the $\kappa$ opioid receptor and with affinities for other opioid receptors, might produce anti-addiction effects with fewer undesirable side effects (Archer et al., 1996; Bart et al., 2005; Kreek et al., 2005; Stevenson et al., 2004). Likewise, developing novel neoclerodane diterpenes with less selectivity for $\kappa$ opioid receptors over other opioid receptors, may lead to a better tolerated side effect profile. Future studies testing this hypothesis may identify effective anti-addiction pharmacotherapies with fewer side effects. Although this study has shown that MOM Sal B has some undesirable side effects including depression and modulation of natural reward. It is also the first to characterise both the antiaddiction and side effect profile for a novel Sal A analogue. This study has demonstrated that longer acting Sal A analogues have anti-addiction effects, a pharmacokinetic improvement over both Sal A and also traditional $\kappa$ opioid agonists. This information is likely to guide further analogue development in future. It is clear that $\mathrm{Sal} \mathrm{A}$ and analogues have different binding and signalling properties compared to traditional $\kappa$ opioid agonists and warrant further investigation. Perhaps the development of "functional agonists" or "mixed agonists" that can modulate $\kappa$ opioid receptor signalling pathways differentially in order to produce the desired anti-addiction effects with reduced side effects.

\section{Acknowledgments}

The authors would like to thank the Health Research Council of NZ, Neurological Foundation of NZ, and National Institute on Drug Abuse (DA018151 to TEP) for funding this study. The content is the sole responsibility of the authors and does not necessarily represent the official views of the National Institute on Drug Abuse, National Institutes of Health. The authors would like to acknowledge the assistance of Prof. Susan Schenk, Mr. Richard Moore, Mr. Caleb Carati and Mr. Alex Crowther.

\section{Reference}

Archer S, Glick SD, Bidlack JM. Cyclazocine revisited. Neurochemical Research. 1996; 21:13691373. [PubMed: 8947927]

Baker LE, Panos JJ, Killinger BA, Peet MM, Bell LM, Haliw LA, Walker SL. Comparison of the discriminative stimulus effects of salvinorin A and its derivatives to U69,593 and U50,488 in rats. Psychopharmacology. 2009; 203:203-211. [PubMed: 19153716]

Bart G, Schluger JH, Borg L, Ho A, Bidlack JM, Kreek MJ. Nalmefene induced elevation in serum prolactin in normal human volunteers: Partial kappa opioid agonist activity? Neuropsychopharmacology. 2005; 30:2254-2262. [PubMed: 15988468] 
Beguin C, Potter DN, DiNieri JA, Munro TA, Richards MR, Paine TA, Berry L, Zhao Z, Roth BL, Xu W, Liu-Chen L-Y, Carlezon WA Jr. Cohen BM. N-methylacetamide analog of salvinorin A: A highly potent and selective kappa-opioid receptor agonist with oral efficacy. Journal of Pharmacology and Experimental Therapeutics. 2008; 324:188-195. [PubMed: 17951511]

Beguin C, Potuzak J, Xu W, Liu-Chen L-Y, Streicher JM, Groer CE, Bohn LM, Carlezon WA Jr. Cohen BM. Differential signaling properties at the kappa opioid receptor of 12-epi-salvinorin A and its analogues. Bioorganic \& Medicinal Chemistry Letters. 2012; 22:1023-1026. [PubMed: 22204910]

Beguin C, Richards MR, Wang YL, Chen Y, Liu-Chen LY, Ma ZZ, Lee DYW, Carlezon WA, Cohen BM. Synthesis and in vitro pharmacological evaluation of salvinorin A analogues modified at $\mathrm{C}(2)$. Bioorganic \& Medicinal Chemistry Letters. 2005; 15:2761-2765. [PubMed: 15869877]

Butelman ER, Mandau M, Tidgewell K, Prisinzano TE, Yuferov V, Kreek MJ. Effects of salvinorin A, a kappa-opioid hallucinogen, on a neuroendocrine biomarker assay in nonhuman primates with high kappa-receptor homology to humans. Journal of Pharmacology and Experimental Therapeutics. 2007; 320:300-306. [PubMed: 17060493]

Butelman ER, Prisinzano TE, Deng H, Rus S, Kreek MJ. Unconditioned behavioral effects of the powerful kappa-opioid hallucinogen salvinorin A in nonhuman primates: Fast onset and entry into cerebrospinal fluid. Journal of Pharmacology and Experimental Therapeutics. 2009; 328:588-597. [PubMed: 19001155]

Butelman ER, Caspers M, Lovell KM, Kreek MJ, Prisinzano TE. Behavioral effects and central nervous system levels of the broadly available kappa-agonist hallucinogen salvinorin A are affected by p-glycoprotein modulation in vivo. Journal of Pharmacology and Experimental Therapeutics. 2012; 341:802-808. [PubMed: 22434677]

Chartoff EH, Potter D, Damez-Werno D, Cohen BM, Carlezon WA Jr. Exposure to the selective kappa-opioid receptor agonist salvinorin A modulates the behavioral and molecular effects of cocaine in rats. Neuropsychopharmacology. 2008; 33:2676-2687. [PubMed: 18185499]

Chavkin C, Sud S, Jin WZ, Stewart J, Zjawiony JK, Siebert DJ, Toth BA, Hufeisen SJ, Roth BL. Salvinorin A, an active component of the hallucinogenic sage Salvia divinorum is a highly efficacious kappa-opioid receptor agonist: Structural and functional considerations. Journal of Pharmacology and Experimental Therapeutics. 2004; 308:1197-1203. [PubMed: 14718611]

De Wit H, Stewart J. Reinstatement of cocaine-reinforced responding in the rat. Psychopharmacology. 1981; 75:134-143. [PubMed: 6798603]

De Wit H, Stewart J. Drug reinstatement of heroin-reinforced responding in the rat. Psychopharmacology. 1983; 79:29-31. [PubMed: 6403961]

Fantegrossi WE, Kugle KM, Valdes LJ, Koreeda M, Woods JH. Kappa-opioid receptor-mediated effects of the plant-derived hallucinogen, salvinorin A, on inverted screen performance in the mouse. Behav. Pharmacol. 2005; 16:627-633. [PubMed: 16286814]

Glick SD, Maisonneuve IM, Raucci J, Archer S. Kappa-opioid inhibition of morphine and cocaine self-administration in rats. Brain Res. 1995; 681:147-152. [PubMed: 7552272]

Gray AM, Rawls SM, Shippenberg TS, McGinty JF. The kappa-opioid agonist, U-69593, decreases acute amphetamine-evoked behaviors and calcium-dependent dialysate levels of dopamine and glutamate in the ventral striatum. J. Neurochem. 1999; 73:1066-1074. [PubMed: 10461896]

Hahn B, Stolerman IP, Shoaib M. Kappa-opioid receptor modulation of nicotine-induced behaviour. Neuropharmacology. 2000; 39:2848-2855. [PubMed: 11044755]

Harden MT, Smith SE, Niehoff JA, McCurdy CR, Taylor GT. Antidepressive effects of the kappaopioid receptor agonist salvinorin A in a rat model of anhedonia. Behav Pharmacol. 2012; 23:710715. [PubMed: 22926298]

Heidbreder CA, Babovicvuksanovic D, Shoaib M, Shippenberg TS. Development of behavioral sensitization to cocaine - influence of kappa-opioid receptor agonists. Journal of Pharmacology and Experimental Therapeutics. 1995; 275:150-163. [PubMed: 7562544]

Heidbreder CA, Goldberg SR, Shippenberg TS. The kappa-opioid receptor agonist U-69593 attenuates cocaine-induced behavioral sensitization in the rat. Brain Res. 1993; 616:335-338. [PubMed: 8395306] 
Hooker JM, Xu Y, Schiffer W, Shea C, Carter P, Fowler JS. Pharmacokinetics of the potent hallucinogen, salvinorin $\mathrm{A}$ in primates parallels the rapid onset and short duration of effects in humans. NeuroImage. 2008; 41:1044-1050. [PubMed: 18434204]

Inan S, Lee DYW, Liu-Chen LY, Cowan A. Comparison of the diuretic effects of chemically diverse kappa opioid agonists in rats: nalfurafine, U50,488H, and salvinorin A. Naunyn-Schmiedebergs Archives of Pharmacology. 2009; 379:263-270.

Kreek MJ, Bart G, Lilly C, Laforge KS, Nielsen DA. Pharmacogenetics and human molecular genetics of opiate and cocaine addictions and their treatments. Pharmacological Reviews. 2005; 57:1-26. [PubMed: 15734726]

Mello NK, Negus SS. Effects of kappa opioid agonists on cocaine- and food-maintained responding by rhesus monkeys. Journal of Pharmacology and Experimental Therapeutics. 1998; 286:812-824. [PubMed: 9694938]

Morani AS, Kivell B, Prisinzano TE, Schenk S. Effect of kappa-opioid receptor agonists U69593, $\mathrm{U} 50488 \mathrm{H}$, spiradoline and salvinorin A on cocaine-induced drug-seeking in rats. Pharmacol. Biochem. Behav. 2009; 94:244-249. [PubMed: 19747933]

Morani AS, Schenk S, Prisinzano TE, Kivell BM. A single injection of a novel kappa opioid receptor agonist salvinorin A attenuates the expression of cocaine-induced behavioral sensitization in rats. Behav. Pharmacol. 2012; 23:162-170. [PubMed: 22293826]

Munro TA, Duncan KK, Xu W, Wang Y, Liu-Chen L-Y, Carlezon WA Jr. Cohen BM, Beguin C. Standard protecting groups create potent and selective kappa opioids: Salvinorin B alkoxymethyl ethers. Bioorganic \& Medicinal Chemistry. 2008; 16:1279-1286. [PubMed: 17981041]

Peet MM, Baker LE. Salvinorin B derivatives, EOM-Sal B and MOM-Sal B, produce stimulus generalization in male Sprague-Dawley rats trained to discriminate salvinorin A. Behav. Pharmacol. 2011; 22:450-457. [PubMed: 21814135]

Pfeiffer A, Brantl V, Herz A, Emrich HM. Psychotomimesis mediated by kappa-opiate receptors. Science. 1986; 233:774-776. [PubMed: 3016896]

Porsolt RD. Animal-model of depression. Biomedicine. 1979; 30:139-140. [PubMed: 573643]

Prevatt-Smith KM, Lovell KM, Simpson DS, Day VW, Douglas JT, Bosch P, Dersch CM, Rothman RB, Kivell B, Prisinzano TE. Potential drug abuse therapeutics derived from the hallucinogenic natural product salvinorin A. MedChemComm. 2011; 2:1217-1222. [PubMed: 22442751]

Prisinzano TE. Psychopharmacology of the hallucinogenic sage Salvia divinorum. Life Sciences. 2005; 78:527-531. [PubMed: 16213533]

Prisinzano TE, Rothman RB. Salvinorin A analogs as probes in opiold pharmacology. Chemical Reviews. 2008; 108:1732-1743. [PubMed: 18476672]

Prisinzano TE, Tidgewell K, Harding WW. kappa Opioids as potential treatments for stimulant dependence. Aaps Journal. 2005; 7:E592-E599. [PubMed: 16353938]

Roth BL, Baner K, Westkaemper R, Siebert D, Rice KC, Steinberg S, Ernsberger P, Rothman RB. Salvinorin A: A potent naturally occurring nonnitrogenous kappa opioid selective agonist. Proceedings of the National Academy of Sciences of the United States of America. 2002; 99:11934-11939. [PubMed: 12192085]

Schenk S, Partridge B, Shippenberg TS. U69593, a kappa-opioid agonist, decreases cocaine selfadministration and decreases cocaine-produced drug-seeking. Psychopharmacology. 1999; 144:339-346. [PubMed: 10435406]

Schenk S, Partridge B, Shippenberg TS. Effects of the kappa-opioid receptor agonist, U69593, on the development of sensitization and on the maintenance of cocaine self-administration. Neuropsychopharmacology. 2001; 24:441-450. [PubMed: 11182539]

Schenk S, Partridge B. Effect of the kappa-opioid receptor agonist, U69593, on reinstatement of extinguished amphetamine self-administration behaviour. Pharmacology Biochemistry and Behavior. 2001; 68(4):629-34.

Schmidt MD, Schmidt MS, Butelman ER, Harding WW, Tidgewell K, Murry DJ, Kreek MJ, Prisinzano TE. Pharmacokinetics of the plant-derived kappa-opioid hallucinogen salvinorin a in nonhuman primates. Synapse. 2005; 58:208-210. [PubMed: 16138318] 
Shippenberg, TS.; Chefer, VI.; Zapata, A.; Heidbreder, CA. Modulation of the behavioral and neurochemical effects of psychostimulants by kappa-opioid receptor systems. In: QuinonesJenab, V., editor. Biological Basis of Cocaine Addiction. 2001. p. 50-73.

Shippenberg TS, Zapata A, Chefer VI. Dynorphin and the pathophysiology of drug addiction. Pharmacol. Ther. 2007; 116:306-321. [PubMed: 17868902]

Slattery DA, Cryan JF. Using the rat forced swim test to assess antidepressant-like activity in rodents. Nature Protocols. 2012; 7:1009-1014.

Stevenson GW, Wentland MP, Bidlack JM, Mello NK, Negus SS. Effects of the mixed-action kappa/ $\mathrm{mu}$ opioid agonist 8-carboxamidocyclazocine on cocaine- and food-maintained responding in rhesus monkeys. Eur. J. Pharmacol. 2004; 506:133-141. [PubMed: 15588733]

Todtenkopf MS, Marcus JF, Portoghese PS, Carlezon WA. Effects of kappa-opioid receptor ligands on intracranial self-stimulation in rats. Psychopharmacology. 2004; 172:463-470. [PubMed: 14727002]

Walsh SL, Geter-Douglas B, Strain EC, Bigelow GE. Enadoline and butorphanol: Evaluation of kappa-agonists on cocaine pharmacodynamics and cocaine self-administration in humans. Journal of Pharmacology and Experimental Therapeutics. 2001; 299:147-158. [PubMed: 11561074]

Wang Y, Chen Y, Xu W, Lee DYW, Ma Z, Rawls SM, Cowan A, Liu-Chen L-Y. 2-methoxymethylsalvinorin $\mathrm{B}$ is a potent kappa opioid receptor agonist with longer lasting action in vivo than salvinorin A. Journal of Pharmacology and Experimental Therapeutics. 2008; 324:1073-1083. [PubMed: 18089845]

Wang Y, Tang K, Inan S, Siebert D, Holzgrabe U, Lee DYW, Huang P, Li JG, Cowan A, Liu-Chen LY. Comparison of pharmacological activities of three distinct kappa ligands (salvinorin A, TRK-820 and 3FLB) on kappa opioid receptors in vitro and their antipruritic and antinociceptive activities in vivo. Journal of Pharmacology and Experimental Therapeutics. 2005; 312:220-230. [PubMed: 15383632]

Wee S, Koob GF. The role of the dynorphin-kappa opioid system in the reinforcing effects of drugs of abuse. Psychopharmacology. 2010; 210:121-135. [PubMed: 20352414] 


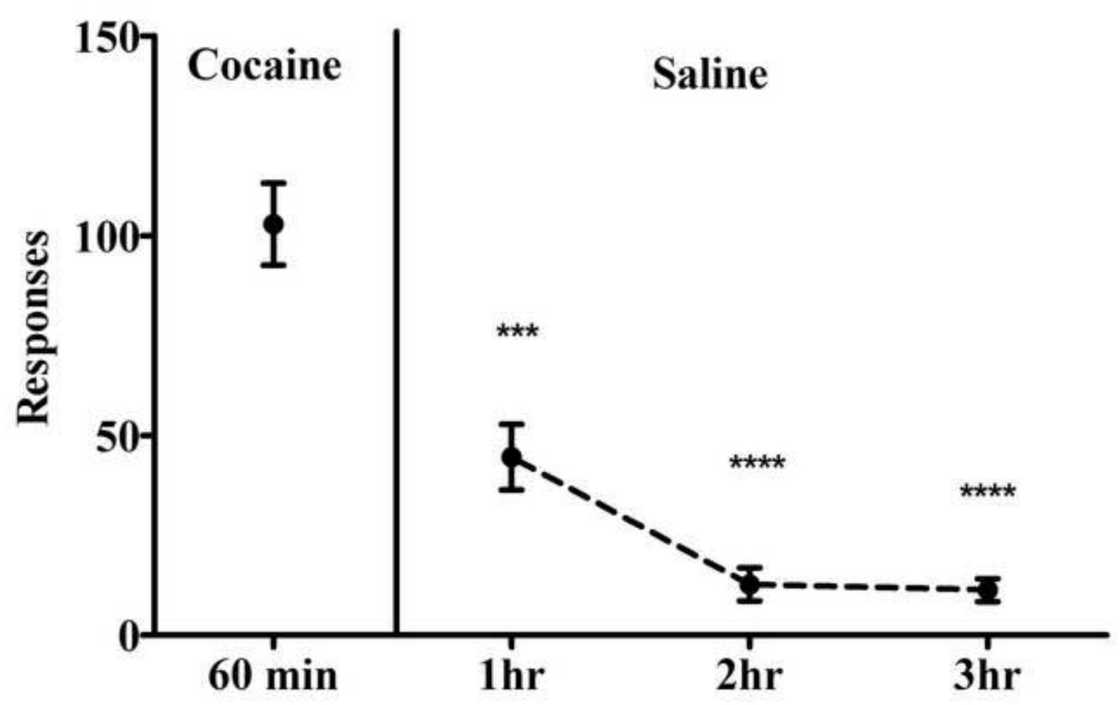

Phase 1

Phase 2

Fig. 1.

Symbols indicate the number of active lever responses ( \pm S.E.M..) produced during selfadministration (phase 1) and extinction (phase 2) of the reinstatement test. Responding was high during phase $1(102.9 \pm 10.3)$. Once cocaine was replaced by saline, responding was reduced by the end of phase $2(11.3 \pm 2.9)$. $(n=7)$. One-way repeated measures ANOVA followed by Bonferroni post-hoc tests were performed (*** $\mathrm{P}<0.001$; **** $\mathrm{P}<0.0001)$. 


\section{Cocaine (20 mg/kg, i.p.)}

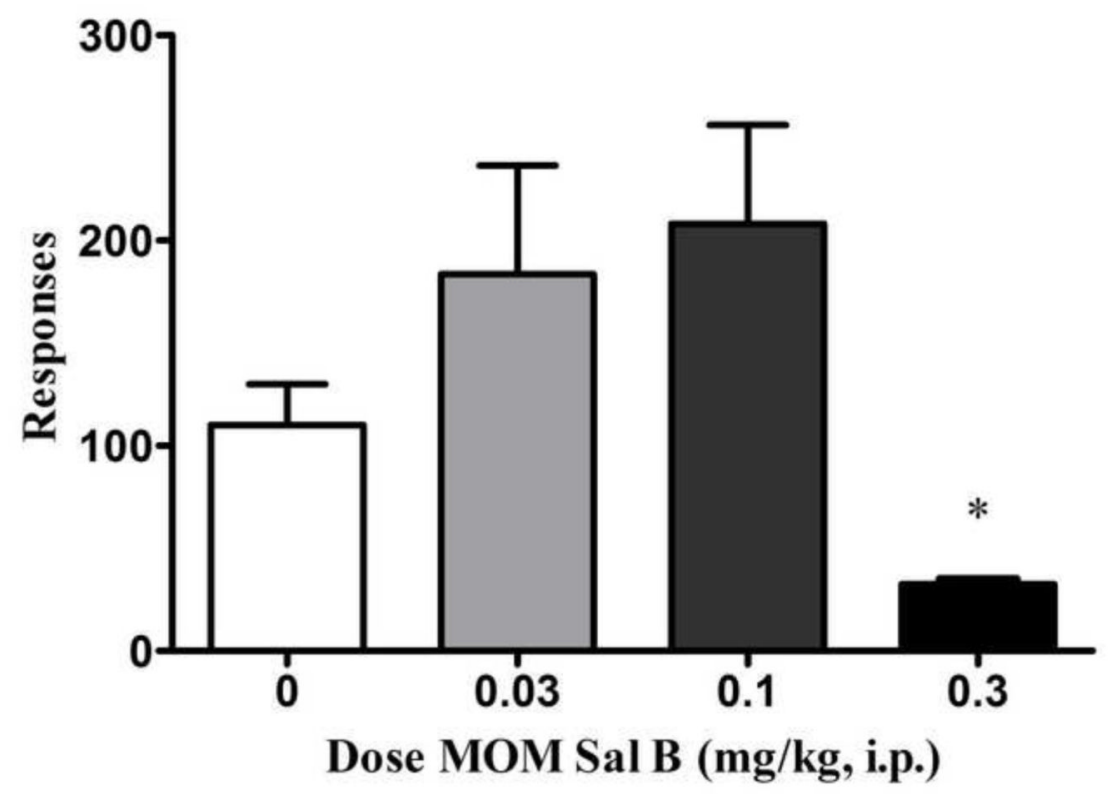

Fig. 2.

Active lever responses (+S.E.M.) produced during phase 3 of the reinstatement test are shown. Rats which displayed extinguished lever pressing behaviour during the extinction phase were treated with different doses of MOM Sal B $(0,0.03,0.1$ and $0.3 \mathrm{mg} / \mathrm{kg})$ followed by a priming injection of cocaine $(20 \mathrm{mg} / \mathrm{kg})$ and saline reinforced responses were recorded for a period of $60 \mathrm{~min}$. $* \mathrm{P}<0.05$, data compared with vehicle treated group $(0 \mathrm{mg} / \mathrm{kg})$. Oneway ANOVA followed by Tukey post hoc test. $n=5$; treatment groups; $n=6$; control group. 


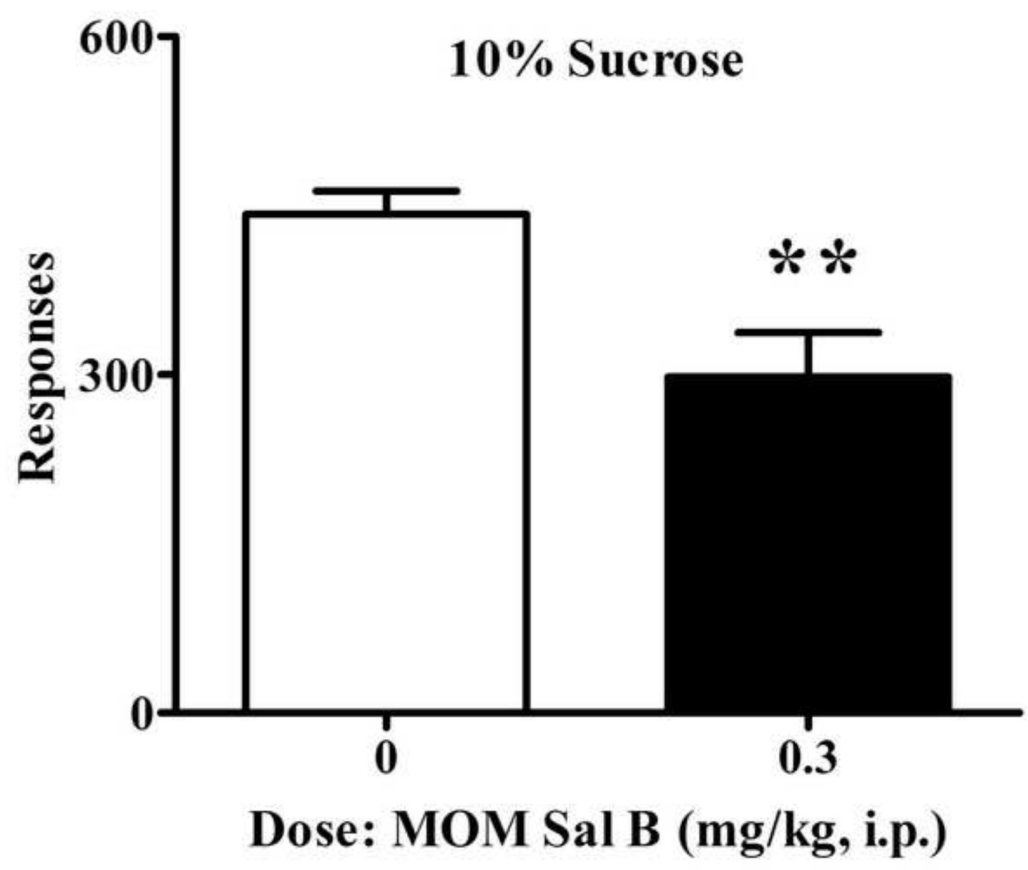

Fig. 3.

Mean lever responses (+S.E.M.) of a $10 \%$ oral sucrose solution following MOM Sal B (0, $0.3 \mathrm{mg} / \mathrm{kg}$ ) treatment are shown. $* * \mathrm{P}<0.01$, data compared to $0 \mathrm{mg} / \mathrm{kg}$. Student $\mathrm{t}$-test. $\mathrm{n}=7$. 
(a)

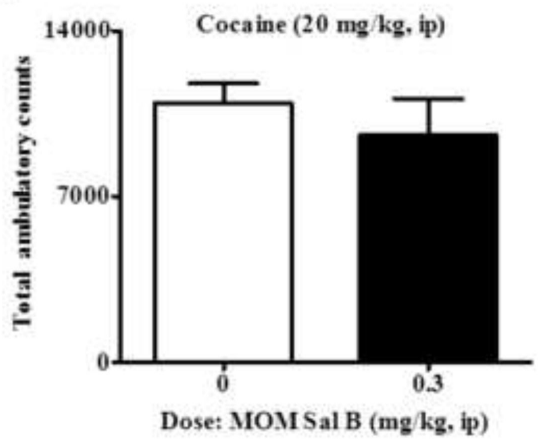

(b)

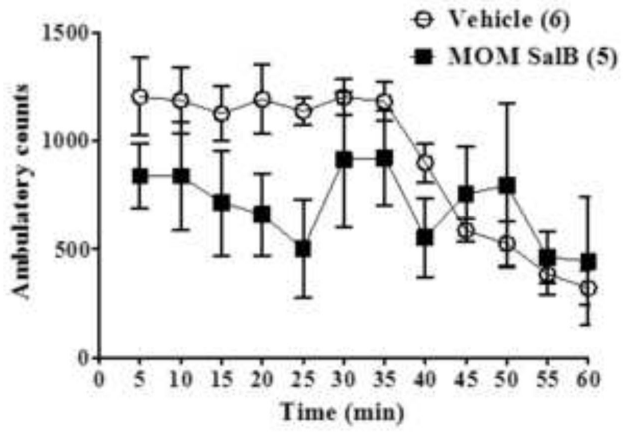

Fig. 4.

Cocaine induced locomotor activity in cocaine self-administering rats. Symbols represent (A) total ambulatory counts (+S.E.M.) and (B) Locomotion at every 5 min interval during the $60 \mathrm{~min}$ time period following $30 \mathrm{~min}$ habituation and vehicle or MOM Sal B $(0,0.3 \mathrm{mg} /$ $\mathrm{kg})$ and cocaine $(20 \mathrm{mg} / \mathrm{kg})$ injections. Student t-test for total ambulation $(\mathrm{P}=0.44)$ and repeated measures two-way ANOVA followed by Bonferroni post-hoc test for 5 min interval data. $\mathrm{n}=5-6)(\mathrm{P}=0.07)$. 
(a)

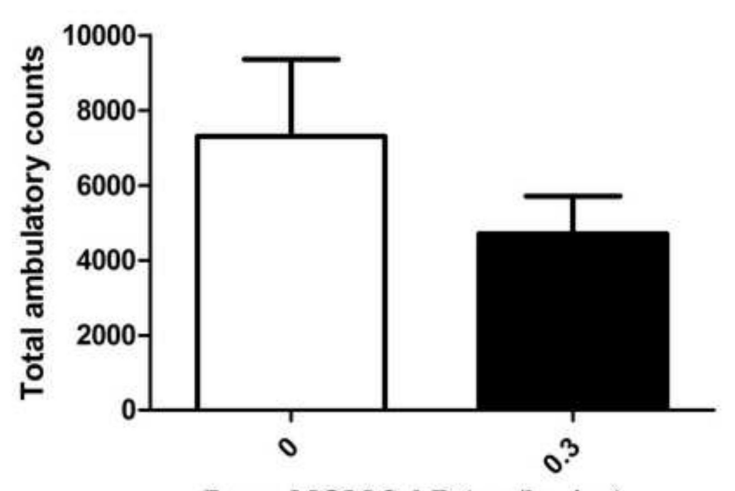

Dose: MOM Sal B (mg/kg, i.p.)

(b)

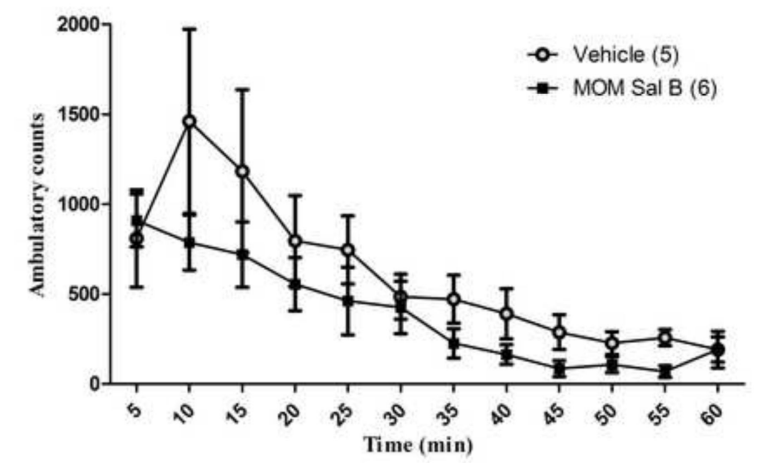

Fig. 5.

Cocaine induced locomotor activity in drug naive rats. Symbols represent (A) total ambulatory counts (+S.E.M.) and (B) Locomotion at every 5 min interval during the $60 \mathrm{~min}$ time period following $30 \mathrm{~min}$ habituation and vehicle or MOM Sal B $(0,0.3 \mathrm{mg} / \mathrm{kg})$ and cocaine $(20 \mathrm{mg} / \mathrm{kg})$ injections. Student t-test for total ambulation and repeated measures two-way ANOVA followed by Bonferroni post-hoc test for 5 min interval data. $n=5-6$ $(\mathrm{P}=0.24)$. 
(a)

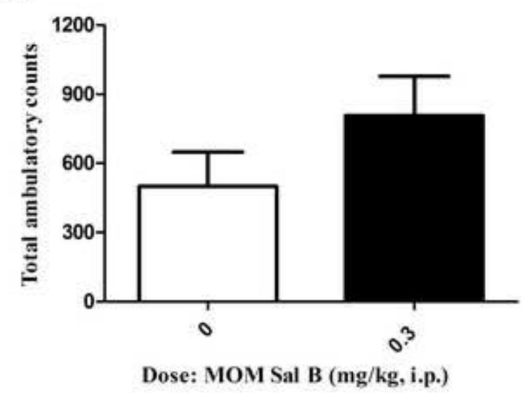

(b)

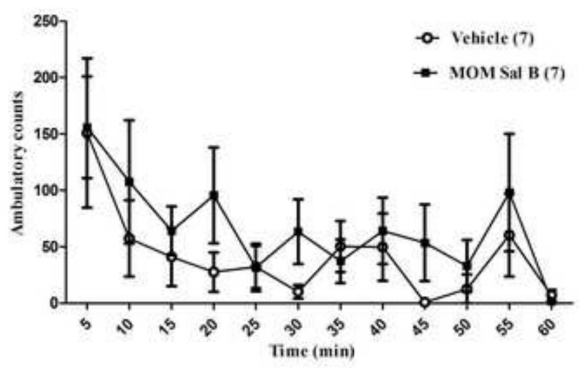

(c)

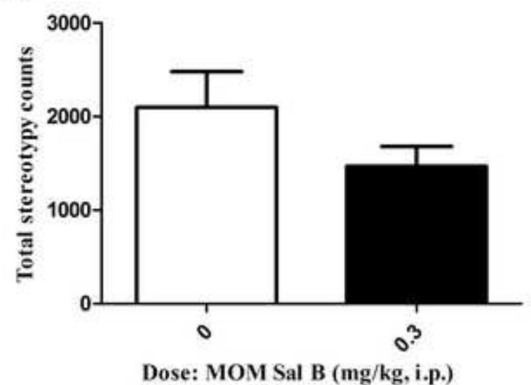

(d)

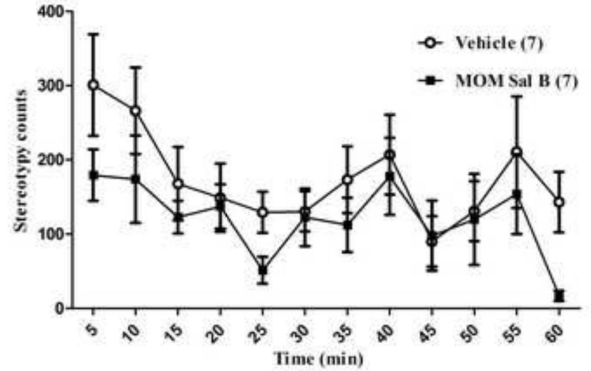

Fig. 6.

Effects of MOM Sal B on locomotor activity in drug naive rats. Symbols represent (A) total ambulatory counts (+S.E.M.) and (B) Locomotion at every $5 \mathrm{~min}$ interval during the $60 \mathrm{~min}$ time period following MOM Sal B treatment and habituation. Total stereotypy counts (C) and (D) at every 5 min time point are shown. Student t-test for total ambulation and stereotypy counts and repeated measures two-way ANOVA followed by Bonferroni posthoc test for 5 min interval data. $\mathrm{n}=7$. 


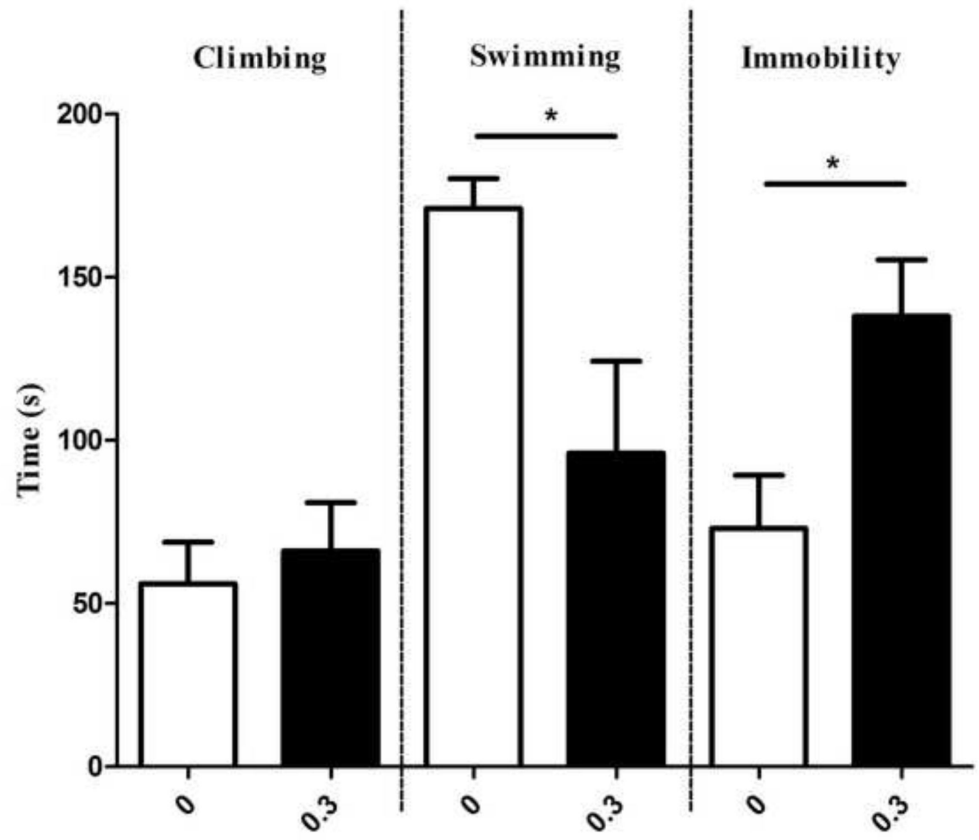

Dose: MOM Sal B (mg/kg, i.p.)

Fig. 7.

Symbols indicate mean lever press responses (+S.E.M.) of climbing, swimming and immobility for $5 \mathrm{~min}$ following MOM Sal B $(0,0.3 \mathrm{mg} / \mathrm{kg})$ treatment. ${ }^{*} \mathrm{p}<0.05$, data compared to $0 \mathrm{mg} / \mathrm{kg}$. Student t-test. $\mathrm{n}=5$ for each group. 